\title{
Migração e classe criativa: evidências para o Brasil com base em uma análise multinomial
}

\author{
Verônica de Castro Lameira ${ }^{1}$ \\ Sibelle Cornélio Diniz?
}

\begin{abstract}
Resumo: Recentemente, a literatura econômica tem incorporado a produção artística, cultural e criativa às amenidades urbanas, ou seja, o conjunto de características e atividades capazes de gerar externalidades positivas sobre residentes e visitantes, elevando seu bem-estar. Do mesmo modo, a concentração da chamada "classe criativa" vem sendo reconhecida como uma vantagem comparativa de certas cidades, facilitando sua inserção competitiva na "economia do conhecimento" e gerando efeitos multiplicadores internos à região ao induzir a substituição de importações. Nessas análises, os trabalhadores culturais e criativos são entendidos como uma classe de alta mobilidade no território, cujas decisões locacionais estariam relacionadas à capacidade de atração e retenção desses trabalhadores das regiões. Este artigo investiga essa hipótese para o Brasil, buscando responder a duas grandes questões: i) a probabilidade de migração desse grupo é diferente conforme a região de destino?;ii) as razões individuais para a migração diferem das dos demais grupos de trabalhadores? São utilizados dados individuais do Censo Demográfico de 2010. Aspectos individuais das decisões migratórias são investigados com base em modelos multinomiais. Os resultados sugerem respostas positivas aos dois questionamentos.
\end{abstract}

Palavras-chave: Logit multinomial. Migração. Trabalhadores culturais.

Classificação JEL: O15, R23, Z11

\begin{abstract}
In recent years, the economic literature has incorporated artistic, cultural and creative production as part of urban amenities, i.e., the set of features and activities that generate positive externalities on residents and visitors, increasing their welfare. Similarly, the concentration of the so-called "creative class"has been recognized as a comparative advantage in certain cities, facilitating competitive entry in the "knowledge economy" and generating internal multiplier effects to the region when inducing import substitution. In these approaches, cultural and creative workers are defined as a class of high mobility whose location decisions are related to the ability of the regions to attract and retain these workers. This article investigates this hypothesis for Brazil, seeking to answer two major questions: i) the probability of migration of this group is higher than of workers in general; ii) their individual reasons for migration differ from other groups of workers? We use individual data from 2010 Demographic Census and municipal sources. The results suggest positive answers to both questions.
\end{abstract}

Keywords: Migration. Cultural workers. Multinomial logit.

JEL Classification: O15, R23, Z11

\section{Introdução}

Recentemente, a literatura econômica tem incorporado a produção artística, cultural e criativa às amenidades urbanas, ou seja, o conjunto de características e atividades capazes de gerar externalidades positivas sobre residentes e visitantes, elevando seu bem-estar (Machado et al., 2013). Do mesmo modo, a concentração de trabalhadores criativos, ou a chamada "classe criativa", vem sendo

\footnotetext{
${ }^{1}$ Doutora em Economia pelo Cedeplar/UFMG. E-mail: lameira.veronica@gmail.com.

2 Doutora em Economia pelo Cedeplar/UFMG. Professora Adjunta do departamento de Economia da Face/UFMG. Email: sibele.diniz@gmail.com.
}

Página 158 Caderno de Ciências Sociais Aplicadas, Vitória da Conquista/BA, vol. 16, n² 27, ano 16, p. 158-186, jan/jun 2019. 
reconhecida como uma vantagem comparativa de certas cidades, facilitando sua inserção competitiva na "economia do conhecimento" (Florida, 2002) e gerando efeitos multiplicadores internos à região ao induzir a substituição de importações via oferta de atividades de entretenimento voltadas aos consumidores regionais (Markusen e Schrock, 2006).

Nessas análises, os trabalhadores culturais e criativos são entendidos como uma classe de alta mobilidade no território, cujas decisões locacionais estariam relacionadas à capacidade de atração e retenção desses trabalhadores das regiões. Este artigo investiga essa hipótese para o Brasil, buscando responder a duas grandes questões: i) a chance de migração desse grupo de trabalhadores é diferente conforme a região de destino?; ii) as razões individuais para a migração desse grupo diferem das dos demais grupos de trabalhadores? Para tanto, são utilizados microdados do Censo Demográfico de 2010.

Os resultados obtidos indicam a importância de características individuais observadas na determinação da migração de trabalhadores, sejam estes criativos ou não. Outro aspecto relevante é a diferença nos efeitos e papéis desempenhados por essas características quando os destinos das migrações são diferentes. Homens e jovens possuem maior chance de realizar qualquer tipo de migração. Indivíduos com ensino superior completo são mais móveis em relação aos demais. Por sua vez, indivíduos brancos são menos propensos à migração para as Regiões Norte, Nordeste e CentroOeste, quando comparados aos indivíduos das demais raças. Por outro lado, apresentam maiores chances de migração para destinos situados nas regiões Sudeste e Sul. Chefes de família possuem maiores chances de migração (aproximadamente 25\%, em média), independentemente da região de destino. Indivíduos com cônjuge apresentam menores chances de realizar migração para quaisquer regiões. Indivíduos com família maior possuem menor chance de migrar para todas as regiões, exceto a região Norte.

Para o caso particular dos profissionais criativos, no que se refere ao grau de instrução, profissionais criativos com ensino superior completo possuem maior chance de migrar para o Sudeste. Outro aspecto relacionado à instrução da classe artística/cultural direta é que os menos escolarizados apresentam maior chance de migração para a Região Norte. Indivíduos com carteira assinada possuem maior chance de estar ocupado na região Norte, em relação aos profissionais não remunerados dessa categoria, e menores chances de estar ocupado nas Regiões Nordeste e Sudeste, diferentemente do que se observou no total de ocupados, quando comparados ao indivíduo não remunerado. Migrantes que trabalham por conta própria apresentam maior possibilidade de ocupação no Nordeste, enquanto para o total de ocupados a região de maior chance de ocupação é o Sudeste.

Página 159 Caderno de Ciências Sociais Aplicadas, Vitória da Conquista/BA, vol. 16, n 27, ano 16, p. 158-186, jan/jun 2019. 
O presente estudo está organizado em quatro seções, além desta introdução. A segunda seção apresenta uma revisão de literatura sobre os determinantes da migração individual pelo motivo trabalho, no que diz respeito às características individuais e da localidade de destino. Em seguida, apresenta-se a literatura relacionada à migração da classe artística/cultural. Descreve-se então a metodologia na terceira seção, passando aos resultados na quarta seção. As considerações finais são realizadas na quinta seção.

\section{Breve revisão da literatura}

A migração de indivíduos ocupados no setor cultural (núcleo ou meio) na data de referência do Censo Demográfico de 2010 pode ser relacionada a uma gama de fatores individuais que, em geral, contribuem para que determinados indivíduos, ocupados ou não em atividades culturais, sejam caracterizados como migrantes. Adicionalmente, existem determinantes específicos da decisão de migração da classe artística. Dessa maneira, as subseções que seguem destacam alguns estudos realizados sobre ambos os temas.

\subsection{Migração e mobilidade laboral ${ }^{3}$}

A migração é compreendida como um processo social intrínseco às sociedades humanas, tendo como "pano de fundo" a conexão cultural, econômica, social e política entre regiões (Hoerder, 2002). Conforme Sjaastad (1962), a mobilidade laboral envolve uma decisão de investimento, na qual prováveis custos e retornos são considerados, sejam estes pecuniários ou não.

Kuznets et al. (1964) sublinham questões relacionadas à seletividade dos migrantes. Segundo os autores, migrantes são propensos a riscos, mais dinâmicos, e com maior capacidade de adaptação a novos ambientes desconhecidos. Ainda sobre a questão da seletividade do migrante, Golgher (2004) adverte que, na média, o migrante não é totalmente similar aos indivíduos que permanecem no mesmo local, este difere em vários atributos pessoais. Conforme o autor, idade, sexo, renda, escolaridade, estado civil, e o tamanho da família são alguns desses aspectos. Desse modo, os jovens são mais móveis do que o restante da população, assim como os mais abastados, pois estes últimos absorveriam mais facilmente os custos da migração em face dos indivíduos com renda menor. De maneira idêntica,

\footnotetext{
${ }^{3}$ Existem determinantes específicos da migração relacionados ao local de vínculo empregatício que não são objeto desse estudo. As autoras estão cientes de que o município de vínculo empregatício pode ou não coincidir com o de residência, assim como a possibilidade da escolha do destino na migração fazer parte de uma preferência relacionada à proximidade dos locais de residência e trabalho.
}

Página 160 Caderno de Ciências Sociais Aplicadas, Vitória da Conquista/BA, vol. 16, n² 27, ano 16, p. 158-186, jan/jun 2019. 
homens apresentam maior propensão a migrar (Pekkala, 2003; Viszt et al., 2001). Famílias menores apresentam maior chance de migrar, enquanto indivíduos casados podem ou não ser mais móveis, a depender do tempo de união.

Outras características individuais, como a escolaridade e a raça, são determinantes da probabilidade de migração. Quanto à educação, pessoas mais escolarizadas tenderiam a migrar mais devido aos menores riscos associados ao deslocamento, uma vez que indivíduos com maior instrução apresentam, em média, maior capacidade de coletar e processar informações pertinentes à escolha (Bover e Arellano, 2002; Mukkala, 2005; Pekkala, 2003; Stambol, 2003; Zimmermann, 2004). No que tange à questão racial, Kulu e Billari (2004) observam que, para o caso da Estônia, indivíduos pertencentes a minorias étnicas tendem a migrar menos, e quando o fazem, esse movimento geralmente ocorre para destinos em que estejam localizados grupos étnicos compatíveis. Esse fato é corroborado pelo estudo de Justo e Silveira Neto (2009) para o caso brasileiro, o qual mostra que migrantes com destino nas regiões Sudeste e Sul do país eram, em sua maioria, de raça branca; e por outro lado, os que se destinavam às regiões Norte e Nordeste eram, em sua maioria, indivíduos pardos e negros.

No que se refere aos aspectos regionais da migração, Lee (1966) resume os fatores que influenciam a decisão de migrar a existência de diversidades entre origem e destino, obstáculos (barreiras físicas ou legais, distância). O autor adverte que um cálculo simples de atração e repulsão não decide o ato de migrar, sendo necessário considerar aspectos individuais. Desse modo, destaca a seletividade da migração, porquanto variáveis como sexo, idade e classe social afetam o modo como as pessoas respondem aos fatores e à capacidade de superar os obstáculos; no entanto, os mesmos fatores não afetam, necessariamente, todas as pessoas de forma semelhante.

Conforme Harris e Todaro (1970), a decisão de migrar é realizada de acordo com a maximização de retornos esperados, considerando a renda real do trabalho. Seria, pois, um movimento em resposta a desequilíbrios na distribuição espacial dos fatores de produção. Os indivíduos frequentemente fazem comparações de rendas pessoais dentro do seu grupo de referência, considerando custos ou benefícios psíquicos, sentimentos de privação ou satisfação relativa. Uma pessoa relativamente mais privada possui incentivo maior a migrar do que a relativamente menos privada; logo, o comportamento migratório não responderia a sentimentos ou vontades independentes (Stark e Bloom, 1985). Já Lucas (2000) argumenta que a migração depende de investimento inicial, não apenas para o transporte, mas para o financiamento na procura do emprego na região de destino.

Página 161 Caderno de Ciências Sociais Aplicadas, Vitória da Conquista/BA, vol. 16, n 27, ano 16, p. 158-186, jan/jun 2019. 
Como o custo de oportunidade desse investimento é menor para famílias mais ricas, membros de famílias com melhores condições financeiras são mais propensos a migrar.

Segundo Golgher (2004), a análise da migração deve considerar características concernentes às regiões, que podem aumentar ou diminuir sua atratividade em relação às demais, sendo tal atratividade determinada por fatores econômicos, políticos, sociais e físicos. Entre essas características, destacam-se as diferenças de salários nas várias regiões, as possibilidades diferenciadas de obtenção de empregos, o custo variável de moradia e de vida, e maiores oportunidades de empregos na indústria.

Por outro lado, Andrienko e Guriev (2004), com base no estudo sobre migração na Rússia, verificam a importância de políticas regionais, amenidades, bem como a disponibilidade de serviços e infraestrutura. Em estudo para Barcelona, Faggian e Royuela (2010) evidenciam relevância da qualidade de vida, cultura, esporte, instalações de educação, transporte público e menor congestionamento.

Outro aspecto importante a ser considerado na migração é a "reversibilidade" desse processo. A decisão de migrar não deve ser considerada irreversível, pois o indivíduo pode migrar mais de uma vez ou, ainda, retornar ao seu lugar de partida para corrigir erros de avaliação na decisão inicial. Segundo Davanzo (1983), somente sob a hipótese de informação completa as chances de uma remigração seriam nulas, visto que o indivíduo saberia perfeitamente os ganhos líquidos da migração.

Outro fator é a possibilidade de um trabalhador migrar para obter conhecimento e voltar para a cidade de origem com possibilidades de conseguir melhores oportunidades de trabalho. Vanderkamp (1971) adverte que razões não econômicas podem levar o indivíduo a decidir voltar para casa e não remigrar para outro lugar, como motivos familiares e afinidades culturais.

\subsection{Migração e trabalhadores culturais/criativos}

A peculiaridade do mercado de trabalho cultural/criativo é ressaltada na literatura da economia da cultura, desafiando os modelos econômicos tradicionais a explicar as decisões desse grupo de trabalhadores. Entre as idiossincrasias dessa inserção ocupacional estão: a busca da flexibilidade, tendo em vista as características do produto e do consumo cultural; várias posições/postos assumidos no mercado de trabalho; menor retorno da escolaridade formal e maior associação do sucesso e do rendimento a processos informais de aprendizado; e menor desigualdade de rendimentos dentro do grupo (Alper e Wassal, 2006; Benhamou, 2003; Menger, 2006; Throsby, 2001).

O comportamento de migração da classe artística parece ser também distinto do dos demais trabalhadores. Markusen e Schrock (2006), em um estudo para as cidades dos Estados Unidos,

Página 162 Caderno de Ciências Sociais Aplicadas, Vitória da Conquista/BA, vol. 16, n 27, ano 16, p. 158-186, jan/jun 2019. 
mostram que a decisão de escolha do local de moradia e de trabalho, pelos artistas, não é guiada necessariamente pela localização de firmas empregadoras, mas também pela existência de uma comunidade artística, pela presença de amenidades culturais e pelo custo de vida na localidade.

Segundo esses autores, parte dos artistas prefere viver nas grandes cidades, onde: i) residentes são mais propensos ao consumo de arte, o que garante a demanda necessária à produção; ii) ocorrem as maiores doações a instituições não governamentais de apoio à cultura; iii) concentram-se as grandes indústrias culturais, como as de mídia e propaganda; iv) atrai-se um maior fluxo de turistas, gerando demanda adicional pela produção artística; v) existem tendências aglomerativas, devido à sinergia entre as diversas atividades artísticas; vi) concentram-se as amenidades oferecidas pelas instituições culturais e pela diversidade e inovatividade das grandes cidades.

Por outro lado, o elevado custo de vida nas grandes metrópoles, bem como as externalidades negativas da aglomeração, podem atrair os artistas (especialmente escritores e artistas visuais) para cidades de pequeno e médio porte, onde são menores os custos de congestionamento e mais abundantes os espaços de recreação (Markusen e Schrock, 2006). Para Florida (2002), as localidades que mais atraem a classe criativa são aquelas mais diversas e abertas a novas ideias e pessoas. Nesse sentido, a tolerância e a oferta de entretenimento local são fatores que influenciam a decisão de localização dessa classe. Para o autor, a classe criativa possui alta mobilidade no território, tendendo a migrar sempre que suas demandas não são totalmente atendidas - como a existência de um "ambiente de negócios" favorável. Kelly e O’Hagan (2007) utilizam o conceito de externalidades marshallianas para explicar a tendência à concentração dos artistas em determinadas regiões, nas quais as sinergias e spillovers intraclasse ocorreriam com maior intensidade. Os autores apontam quatro conjuntos de fatores regionais determinantes dessa concentração: i) a 'riqueza' da localidade, uma vez que as remunerações mais altas implicariam maior demanda por cultura; ii) 'liberdade artística', dada pela concorrência ou pelo tamanho do mercado cultural; iii) acontecimentos fortuitos, como o nascimento de um artista talentoso e influente em determinada cidade; e iv) existência de fatores de produção, como recursos humanos, capital e infraestrutura, especialmente a artística.

Rallet e Torre (1998) apontam o conhecimento tácito como essencial para certas atividades de alto cunho inovador, como as artísticas. O conhecimento transmitido apenas pelo contato face a face não pode ser codificado e transferido por meios eletrônicos, exigindo, portanto, a concentração geográfica. Já Porter (1990) trata a importância da competição decorrente da proximidade geográfica

Página 163 Caderno de Ciências Sociais Aplicadas, Vitória da Conquista/BA, vol. 16, n 27, ano 16, p. 158-186, jan/jun 2019. 
entre firmas, grupos ou indivíduos como artistas, acadêmicos e atletas - tal rivalidade "exige" que todos elevem a qualidade de seus trabalhos, com ganhos generalizados.

São raros os estudos empíricos que investigam diretamente a migração de artistas/trabalhadores criativos. Kelly e O’Hagan (2007) apontam a tendência à concentração de artistas 'proeminentes' em grandes cidades europeias, como Paris e Londres. Markusen e Shrock (2006) mostram que, nos Estados Unidos, a maior concentração ocorre em New York, Los Angeles e San Francisco - os autores concluem que a distribuição espacial dos artistas não se relaciona necessariamente ao tamanho e nem ao crescimento populacional das cidades.

Hansen e Niedomysl (2008), em estudo para a Suécia, verificam que as taxas de migração da classe criativa são apenas marginalmente superiores às dos demais grupos, e que essa classe se move mais pela oferta de emprego que por características do destino. Os autores concluem que as evidências empíricas para o país contradizem a teoria da "classe criativa", para a qual o comportamento migratório dessa classe difere dos demais grupos.

Martin-Brelot et al. (2010) encontram uma mobilidade espacial da classe criativa nos países da Europa menor que a sugerida por Florida para os Estados Unidos - o que é atribuído pelos autores a barreiras culturais, como a língua e os costumes, e institucionais, como diferenças nas políticas de bemestar. Os autores enfatizam as trajetórias e características individuais como determinantes cruciais da decisão de migrar - na Europa, os trabalhadores seriam mais ligados aos locais onde nasceram e estudaram - o que explica em parte a baixa migração entre os países europeus e também a migração intranacional. Para eles, a hipótese de Florida se adéqua melhor aos trabalhadores mais jovens e sem família constituída.

Já Boschma e Fritz (2009) encontram relação positiva entre um clima regional de "tolerância" e "abertura" e a presença de trabalhadores criativos na Europa. Essa relação é testada por Golgher (2011) para as regiões metropolitanas do Brasil, não sendo corroborada. O autor, no entanto, encontra uma correlação positiva entre a oferta de entretenimento e a presença de trabalhadores qualificados nas metrópoles brasileiras.

Queiroz e Golgher (2008) identificam maior procura, pelos indivíduos qualificados, por regiões com mais amenidades urbanas, como melhores condições climáticas, de moradia e lazer, e com ausência de amenidades negativas, como congestionamento do trânsito, crime e poluição. Da Mata et al. (2007) indicam que os migrantes qualificados procuram destinos com maiores salários, menor violência, menor desigualdade social, invernos e verões menos rigorosos, e proximidade do litoral.

Página 164 Caderno de Ciências Sociais Aplicadas, Vitória da Conquista/BA, vol. 16, n² 27, ano 16, p. 158-186, jan/jun 2019. 


\section{Descrição da base de dados e metodologia}

\subsection{Dados e variáveis}

Para a consecução dos objetivos propostos, são utilizados os microdados do Censo Demográfico de 2010, realizado pelo Instituto Brasileiro de Geografia e Estatística (IBGE). O Censo de 2010 constitui importante fonte ao estudo da migração, uma vez que possui perguntas específicas em seu questionário como "município de residência anterior", "tempo de moradia no município", "residência em 31/07/2005", Unidade da Federação, Região de residência em uma data fixa, 31 de julho de 2005, e País de residência anterior, as quais permitem ampla possibilidade de pesquisas relacionadas à mobilidade em distintos recortes geográficos. Ademais, tal fonte de dados possibilita abrangência dos setores de atividade laboral formal e informal, contribuindo para uma análise mais ampla do mercado de trabalho, e possibilitando a análise migratória de profissionais criativos com grau de formalidade variado. A principal desvantagem dessa base de dados repousa em sua periodicidade decenal, se comparada a outras bases de dados para o estudo da migração, como a Pesquisa Nacional por Amostra de Domicílios (PNAD), elaborada pelo IBGE, e a Rais-Migra, do Ministério do Trabalho e Emprego.

Almejando alcançar os objetivos propostos neste estudo, alguns filtros foram feitos na amostra inicial para se obter estimativas corretas quanto aos determinantes individuais da propensão a migrar segundo diferentes regiões de destino. A amostra selecionada é composta apenas por indivíduos ocupados, com idade entre 25 e 65 anos, tendo em vista que pessoas com idade inferior a esta podem fazer parte de uma escolha migratória do chefe do domicílio, e não autônoma. Pessoas acima de 65 anos geralmente não migram almejando colocação em postos de trabalho no destino, sendo esta, em alguns casos, relacionada a outro tipo de mobilidade, como a migração de retorno, que não é objeto de análise neste estudo. Indivíduos cujo rendimento no trabalho principal era acima de $\mathrm{R} \$ 300.000,00$ ou residentes em domicílios cuja renda total era acima de $\mathrm{R} \$ 800.000,00$ foram excluídos da amostra. De modo semelhante, indivíduos que não declararam cor, nível de instrução, tamanho da família também foram retirados da amostra. Dessa maneira, a amostra final é composta por 6.954 .448 pessoas ocupadas, correspondendo a uma população estimada de 66.185.492 indivíduos, conforme os pesos amostrais disponibilizados no Censo para cada pessoa entrevistada.

O critério de migração utilizado é o de data fixa, em que o respondente identifica seu município de residência em uma data de referência predeterminada (31/07/2005). Já os não migrantes são

Página 165 Caderno de Ciências Sociais Aplicadas, Vitória da Conquista/BA, vol. 16, n² 27, ano 16, p. 158-186, jan/jun 2019. 
indivíduos cujo município de residência há cinco anos era o mesmo município na data da entrevista (31/07/2010). A principal vantagem ao utilizar esse critério de migração é a eliminação do problema de referência temporal intrínseco à informação sobre o "município de residência anterior" (Cunha, 2012). Por exemplo, caso fosse utilizado o critério município de residência anterior distinto ao município de residência atual, poderíamos estar comparando um indivíduo específico, caracterizado como migrante com tempo de residência diferente de outro indivíduo também caracterizado migrante, havendo a necessidade de se controlar pelo tempo de residência nas estimações.

Outra vantagem importante ao utilizar dados de migração de curto prazo é identificado por Newbold (2001). Conforme o autor, fatores como os níveis educacionais, estado civil e características no mercado de trabalho, são menos prováveis de sofrerem grandes alterações no curto espaço de tempo e, por isso, podem explicar melhor a mobilidade dos indivíduos. A desvantagem ocorre por não se conseguir apreender de forma completa a remigração planejada, ou seja, aquela em que o indivíduo programou a sua volta após ter obtido o retorno financeiro desejado com a migração. Para esse tipo, pressupõe-se a necessidade de um tempo maior de moradia no local de destino. O Quadro 1 apresenta a relação das variáveis utilizadas nos modelos empíricos.

Quadro 1: Relação das variáveis explicativas utilizadas

\begin{tabular}{|c|c|}
\hline Variáveis & Descrição \\
\hline Dependente & $\begin{array}{l}\text { Variável Policotômica: } 1 \text { se migrante N; } 2 \text { se migrante NE; } 3 \text { se migrante região SE, } 4 \text { se } \\
\text { migrante SUL, e } 5 \text { se migrante CO; } 0 \text { se não for migrante }\end{array}$ \\
\hline Idade & Em anos completos na data de referência $(31 / 07 / 2010)$. \\
\hline Idade $^{2}$ & dade ao quadrado. \\
\hline Homem & Dummy que assume valor 1 se indivíduo for do sexo masculino e 0 caso contrário. \\
\hline Chefe & Dummy que assume valor 1 se indivíduo for chefe do domićlio e 0 caso contrário. \\
\hline Raça & $\begin{array}{l}\text { Dummy que assume valor } 1 \text { se indivíduo for branco e } 0 \text { caso contrário (negro, pardo, } \\
\text { amarelo ou indígena). }\end{array}$ \\
\hline Casado & Dummy que assume valor 1 se indivíduo for casado e 0 caso contrário. \\
\hline Tama & Número de residentes no domicílio \\
\hline Instrução & $\begin{array}{l}\text { Foram criadas } 4 \text { dummies: sem instrução ou fundamental incompleto (referência), } \\
\text { fundamental completo e médio incompleto, médio completo e superior incompleto, e } \\
\text { superior completo. }\end{array}$ \\
\hline Grau de formalidade & $\begin{array}{l}\text { Dummy que assume valor } 1 \text { se o indivíduo é empregado com carteira de trabalho } \\
\text { assinada, militar ou funcionário público ou empregador, e } 0 \text { se o indivíduo é empregado } \\
\text { sem carteira de trabalho assinada, conta própria, não remunerado ou trabalhador na } \\
\text { produção para o próprio consumo. }\end{array}$ \\
\hline
\end{tabular}

A variável dependente é policotômica e construída com base no critério data fixa. Consiste na probabilidade de migrar entre as cinco regiões brasileiras (Norte, Nordeste, Sudeste, Sul e CentroOeste), considerando o local de destino do migrante. Desse modo, são considerados migrantes apenas

Página 166 Caderno de Ciências Sociais Aplicadas, Vitória da Conquista/BA, vol. 16, n² 27, ano 16, p. 158-186, jan/jun 2019. 
indivíduos que na data de referência da pesquisa (31/07/2010) residiam em Região diferente da Região de residência na data fixa (31/07/2005), em que a variável dependente assume as seguintes categorias: 0 se não for migrante, isto é, o indivíduo que na data de referência da pesquisa reside na mesma região em que residia na data fixa; 1 Se o indivíduo reside na região Norte atualmente, e na data fixa residia em outra região; 2 Se o indivíduo reside na região Nordeste e na data fixa residia em outra região; 3 se o indivíduo reside na região Sudeste e na data fixa residia em região diferente da Sudeste; 4 se o indivíduo reside na região Sul e na data fixa residia em outra região; 5 se o indivíduo reside na região CentroOeste e na data fixa residia em região diferente do Centro-Oeste.

Migrantes intrarregionais, intraestaduais, intramicrorregionais, e intermunicipais são caracterizados como não migrantes pelo critério de migração adotado. Em outras palavras, assumem valor zero na categoria da variável dependente. Cumpre advertir para o fato de termos algumas possibilidades, como por exemplo, um indivíduo ter migrado entre duas unidades federativas situadas em regiões diferentes e ser caracterizado como um migrante interestadual e ao mesmo tempo ser migrante interregional. Nesse caso em particular teríamos um migrante interestadual que também é um migrante interregional $1^{4}$ Esse indivíduo é caracterizado como migrante uma vez que, de outro modo, estaríamos procedendo em subestimação do fenômeno em análise.

No que se refere às variáveis explicativas, ampla literatura tem pesquisado sobre os determinantes desse tipo de mobilidade (por exemplo, Sjaastad, 1962; Sahota, 1968; Stark e Bloom, 1985; Golgher, 2004). Desse modo, são selecionadas variáveis que podem influenciar as decisões de migração. A idade em geral apresenta relação negativa com a propensão a migrar (Bover e Arellano, 2002; Golgher, 2004; Hazans, 2003; Oberg, 2001; Sjaastad, 1962). Geralmente, pessoas mais jovens tendem a ser mais móveis do que o restante da população (Golgher, 2004). Nesse sentido, espera-se sinal negativo dessa variável. O termo quadrático dessa variável busca captar não linearidade da migração em relação à idade.

Homens apresentam, em média, maior propensão a migrar (Viszt et al., 2001; Pekkala, 2003; Silveira Neto e Magalhães, 2004). Por sua vez, é esperado sinal positivo para variável homem, a qual busca captar diferenciais de sexo na probabilidade de migração. De maneira adicional, espera-se que chefes de domicílio apresentem maior chance de mobilidade.

\footnotetext{
${ }^{4}$ Esse raciocínio se estende para outros níveis de análise, como mesorregião, microrregião ou município.
}

Página 167 Caderno de Ciências Sociais Aplicadas, Vitória da Conquista/BA, vol. 16, n² 27, ano 16, p. 158-186, jan/jun 2019. 
A variável branco busca apreender diferenciação racial dos migrantes em relação aos locais de destino, uma vez que questões relacionadas à raça são apontadas como pertinentes às escolhas relacionadas à migração (Greenwood, 1975), e portanto são acrescidas às demais covariadas na análise empírica.

Indivíduos casados possuem maiores custos para migrar (Mincer, 1993). Nesse sentido, a variável casado busca verificar se a situação conjugal possui influência sobre a migração. Espera-se sinal de coeficiente negativo para essa variável, uma vez que indivíduos casados têm, em média, maiores vínculos relacionados à região de origem e maiores custos pecuniários para realizar mudança de local de residência.

Aspectos relacionados às características ocupacionais dos trabalhadores são inseridos como determinantes da migração, uma vez que esta representa um importante processo para selecionar trabalhadores no mercado de trabalho inter-regional (Fielding, 1992). Sendo a posição na ocupação relacionada com a migração em virtude da concentração espacial das atividades laborais (Shearmur, 2006). Desse modo, acredita-se que indivíduos com carteira de trabalho assinada, militares ou funcionários públicos ou empregadores sejam mais propensos à migração, uma vez que migrantes são indivíduos com maiores habilidades, motivação e que o fato de ser empregador, funcionário público ou ter carteira assinada indica a possibilidade de sucesso na migração ou que a mesma possa ter ocorrido como resultado de aprovação em concursos públicos, ainda que não seja possível fazer tal assertiva. Desse modo, esperamos que uma melhor posição na ocupação se reflita em maior chance de mobilidade, uma vez que os custos inerentes às mobilidades seriam compensados.

Em relação à escolaridade, estudos apontam correlação positiva da educação com a probabilidade de migrar (Dahl, 2004; Faggian \& Mccann, 2009; Hazans, 2003; Sahota, 1968; Stambol, 2003; Stark e Bloom, 1985; Zimmermann, 2004). Entretanto, Sahota (1968) alude ao fato de que embora indivíduos educados sejam mais móveis e atentos às oportunidades de mudança, em geral, regiões com maiores possibilidades de ganhos pecuniários são também as regiões de alta educação, e dessa maneira, migrantes mais educados na origem têm de competir com os indivíduos educados da região de destino, ceteris paribus, o que impossibilita a previsão do sinal dessa variável a priori.

Página 168 Caderno de Ciências Sociais Aplicadas, Vitória da Conquista/BA, vol. 16, n² 27, ano 16, p. 158-186, jan/jun 2019. 
A definição de trabalhador cultural adotada segue o trabalho de Markusen e Schrock $(2006)^{5}$ : é considerado trabalhador cultural aquele envolvido na produção de bens culturais, ou seja, produtos com alto conteúdo simbólico e que transmitem significados e valores de quem os produziu. Esse grupo subdivide-se em: trabalhadores diretamente envolvidos na produção cultural (“core”: 'criadores' ou 'artistas') e trabalhadores indiretamente envolvidos na produção cultural (“related”: atividades de apoio). Seguindo os mesmos autores, o foco do trabalho é sobre o primeiro subgrupo, ou seja, os trabalhadores culturais "diretos" ("core"). As ocupações consideradas estão no Quadro 2.

Quadro 2: Ocupações definidas como direta ou indiretamente ligada ao setor cultural

\begin{tabular}{|c|c|c|}
\hline \multicolumn{3}{|c|}{ TRABALHADORES DIRETOS (core) } \\
\hline Artes plásticas & 2651 & Artistas plásticos \\
\hline \multirow{6}{*}{ Artes performáticas } & 2652 & Músicos, cantores e compositores \\
\hline & 2653 & Bailarinos e coreógrafos \\
\hline & 2654 & Diretores de cinema, de teatro e afins \\
\hline & 2655 & Atores \\
\hline & 2659 & Artistas criativos e interpretativos não classificados anteriormente \\
\hline & 7312 & Confeccionadores e afinadores de instrumentos musicais \\
\hline Escritores & 2641 & Escritores \\
\hline \multirow{3}{*}{ Artesanato } & 7317 & Artesãos de pedra, madeira, vime \\
\hline & 7318 & Artesãos de tecidos, couros e materiais semelhat \\
\hline & 7319 & Artesãos não classificados an \\
\hline \multicolumn{3}{|c|}{ TRABALHADORES INDIRETOS (related) } \\
\hline \multirow{2}{*}{ Artes performáticas } & 2354 & Outros professores de música \\
\hline & 2355 & Outros professores de artes \\
\hline \multirow{6}{*}{$\begin{array}{l}\text { Artes plásticas } \\
\text { visuais }\end{array}$} & 3432 & Desenhistas e decoradores de interiores \\
\hline & 3431 & Fotógrafos \\
\hline & 2621 & Arquivologistas e curadores de museus \\
\hline & 2622 & Bibliotecários, documentaristas e afins \\
\hline & 3433 & Técnicos em galerias de arte, museus e bibliotecas \\
\hline & 4411 & Trabalhadores de bibliotecas \\
\hline \multirow{4}{*}{$\begin{array}{l}\text { Mídia } \\
\text { comunicação }\end{array}$} & 2642 & Jornalistas \\
\hline & 2643 & Tradutores, intérpretes e linguistas \\
\hline & 2656 & Locutores de rádio, televisão e outros meios de comunicação \\
\hline & 3521 & Técnicos de radiodifusão e gravação audiovisual \\
\hline \multirow{3}{*}{ Artes gráficas } & 7321 & Trabalhadores da pré-impressão gráfica \\
\hline & 7322 & Impressores \\
\hline & 7323 & Encadernadores e afins \\
\hline \multirow[t]{2}{*}{ Outros } & 3435 & $\begin{array}{l}\text { Outros profissionais de nível médio em atividades culturais e } \\
\text { artísticas }\end{array}$ \\
\hline & 1431 & Gerentes de centros esportivos, de diversão e culturais \\
\hline
\end{tabular}

Fonte: Elaboração própria com base na COD 2010.

\footnotetext{
5 Os autores apresentam uma classificação distinta da de Florida (2002) - para eles, a definição de 'classe criativa' estaria relacionada principalmente à escolaridade superior, característica não necessariamente observável na classe artística. Neste trabalho, os termos 'cultural' e 'criativo' são tratados como sinônimos.
}

Página 169 Caderno de Ciências Sociais Aplicadas, Vitória da Conquista/BA, vol. 16, n 27, ano 16, p. 158-186, jan/jun 2019. 
A definição das ocupações relacionadas à classe cultural foi feita com base na Classificação de Ocupações - COD - 2010, do IBGE. Note-se que o Censo 2010 capta a ocupação apenas para o trabalho principal, o que impede a inclusão daqueles que têm as atividades culturais como segunda ou terceira ocupação.

\subsection{Estratégia empírica: O modelo Logit Multinomial}

Constituindo o objetivo principal deste estudo a investigação da probabilidade de um indivíduo migrar entre as cinco grandes regiões do Brasil, será utilizado um modelo de escolha discreta cuja variável resposta é policotômica, a qual assumirá cinco possibilidades como descrito anteriormente. Dessa forma, a variável dependente, a escolha migratória, será um dos seguintes resultados não ordenados: i) se migrou para a Região Norte; ii) se migrante do Nordeste; iii) se migrante da Região Sudeste; iv) se migrante da Região Sul; v) se migrante da região Centro-Oeste; 0 se não for migrante.

Modelos multinomiais são utilizados quando a variável dependente é policotômica, isto é, variáveis categóricas que podem ser classificadas em mais de duas categorias. Isto é, o indivíduo i possui j alternativas e escolhe a alternativa que maximiza sua utilidade. Em que a utilidade para um migrante de uma alternativa é especificada como uma função linear das características do indivíduo e os atributos da alternativa, somando-se um termo de erro.

O modelo Logit Multinomial, um entre outros modelos multinomiais, requer que o princípio da Independência de Alternativas Irrelevantes (I.I.A.) seja atendido. Essa hipótese pressupõe que a decisão entre duas alternativas seja independente da existência de outras alternativas. Porém, caso todas as alternativas apresentem um padrão de substituição essa hipótese não será atendida, o que em alguns casos não se torna um problema. Para testar se a condição da Independência de Alternativas Irrelevantes está sendo cumprida, utiliza-se o teste de Hausman, cuja hipótese nula é de validade da I.I.A.

O teste consiste em omitir uma categoria da variável dependente, fazer a regressão sem a presença dessa categoria omitida e comparar os valores dos coeficientes obtidos com os valores dos coeficientes obtidos na regressão com todas as categorias presentes. Caso os coeficientes sejam diferentes estatisticamente, a hipótese nula é rejeitada.

O objetivo inerente ao Logit Multinomial é comparar, simultaneamente, duas categorias; uma categoria específica, na qual o indivíduo é caracterizado como migrante $(j>1)$ com a categoria de referência, não migrante $(\mathrm{j}=1)$. À semelhança do modelo logit binário, uma probabilidade está associada

Página 170 Caderno de Ciências Sociais Aplicadas, Vitória da Conquista/BA, vol. 16, n 27, ano 16, p. 158-186, jan/jun 2019. 
a cada categoria de resposta $j$ ou categoria de migrante. Essa probabilidade representa a chance de um indivíduo pertencer à categoria específica.

Assumindo que $\sum_{\mathrm{j}=1}^{\mathrm{J}} \mathrm{P}_{\mathrm{ij}}=1$ para qualquer $\mathrm{i}$, e sendo $\beta_{1}=0$, temos a representação da probabilidade do indivíduo i escolher a alternativa j será dada pela equação 1:

$$
\operatorname{Pr}\left(y_{i}=j \mid x_{i}\right)=P_{i j}=\frac{e^{x_{i}^{\prime} \beta_{j}}}{1+\sum_{j=2}^{J} e^{x_{i}^{\prime} \beta_{j}}}, \text { para } j>1
$$

Os coeficientes estimados pelo modelo logit multinomial, obtidos com base no método de máxima verossimilhança, representarão mudanças relativas das probabilidades em relação à categoria de referência, neste estudo, o não migrante. Uma variação de uma unidade em alguma variável explicativa, todas as demais covariáveis constantes fornecerão tais mudanças.

Geralmente, utiliza-se a razão de riscos relativa (R.R.R.). Caso Y $i$ seja uma variável dummy, a R.R.R. é dada pela expressão abaixo:

$$
\ln \left(\begin{array}{l}
\frac{p_{j} \mid y_{i=1}}{p_{1} \mid y_{i=1}} \\
p_{j} \mid y_{j=0} \\
p_{1} \mid y_{i=0}
\end{array}\right)(2)
$$

e para variáveis contínuas a R.R.R é dada pela expressão (3):

$$
\ln \left(\frac{\frac{p_{j} \mid y_{i}=y_{j}^{0}+1}{p_{1} \mid y_{i}=y_{j}^{0}+1}}{\frac{p_{j} \mid y_{i}=y_{i}^{0}}{p_{1} \mid y_{i}=y_{i}^{0}}}\right) \text { (3) }
$$

em que a categoria 0 é a categoria referência.

\section{Resultados e discussão}

\subsection{Estatísticas descritivas}

Os trabalhadores no setor cultural (diretos - "core") correspondiam a 0,61\% da PEA ocupada no Brasil em 2010, o que equivale a cerca de 403.608 trabalhadores. Nas Regiões Metropolitanas, esse percentual se eleva para $0,68 \%$, indicando uma relativa concentração (ainda que pequena) nessas regiões. O percentual mantém-se relativamente estável entre as Grandes Regiões, variando de 0,5\% (Norte) a $0,67 \%$ (Nordeste).

Página 171 Caderno de Ciências Sociais Aplicadas, Vitória da Conquista/BA, vol. 16, n 27, ano 16, p. 158-186, jan/jun 2019. 


\section{- Cadernos de CiêncIas SOCIAIS APLICADAS}

As tabelas 1 e 2 resumem as características individuais dos trabalhadores da cultura e do total de trabalhadores ocupados no Brasil, em 2010. Os dados indicam que o fenômeno da migração, entre os trabalhadores da cultura, parece ocorrer com maior frequência entre homens, não casados, brancos, mais jovens, de maior escolaridade e maior rendimento. Note-se que esse padrão é muito próximo ao observado para o total de ocupados.

Tabela 1: Características dos trabalhadores do setor cultural

\begin{tabular}{l|c|c|c|c}
\hline \hline & \multicolumn{2}{|c|}{ Diretos } & \multicolumn{2}{c}{ Indiretos } \\
\cline { 2 - 4 } & \multicolumn{1}{|c|}{ Migrantes } & Total & Migrantes & Total \\
\hline Responsáveis pelo domicílio (\%) & 46,0 & 48,0 & 46,7 & 44,5 \\
Casado (\%) & 44,8 & 38,5 & 40,0 & 39,3 \\
Branco (\%) & 55,4 & 57,4 & 56,1 & 53,7 \\
Homem (\%) & 43,1 & 46,8 & 45,0 & 46,6 \\
Nível de instrução - Sem instrução e fundamental & & & \\
incompleto (\%) & 34,1 & 27,9 & 27,9 & 28,7 \\
Nível de instrução - Fundamental completo e & & & \\
médio incompleto (\%) & 18,7 & 19,6 & 18,6 & 20,2 \\
Nível de instrução - Médio completo e superior & & & & \\
incompleto (\%) & 34,8 & 39,1 & 37,3 & 36,2 \\
Superior completo (\%) & 12,4 & 13,4 & 16,2 & 14,9 \\
Idade (média) & 41,6 & 39,1 & 37,9 & 37,7 \\
Idade (desvio-padrão) & 10,8 & 10,4 & 10,0 & 10,1 \\
Rendimento do trabalho principal (média) & $\mathrm{R} \$ 1.082,46$ & $\mathrm{R} \$ 1.212,43$ & $\mathrm{R} \$ 1.119,03$ & $\mathrm{R} \$ 1.063,74$ \\
Rendimento do trabalho principal (desvio padrão) & $\mathrm{R} \$ 2.083,66$ & $\mathrm{R} \$ 2.478,85$ & $\mathrm{R} \$ 1.561,38$ & $\mathrm{R} \$ 1.332,10$ \\
Rendimento domiciliar per capita (média) & $\mathrm{R} \$ 1.238,80$ & $\mathrm{R} \$ 1.286,62$ & $\mathrm{R} \$ 1.239,05$ & $\mathrm{R} \$ 1.129,32$ \\
Rendimento domiciliar per capita (desvio padrão) & $\mathrm{R} \$ 3.534,13$ & $\mathrm{R} \$ 1.962,46$ & $\mathrm{R} \$ 1.793,49$ & $\mathrm{R} \$ 1.352,16$ \\
Número de pessoas na família (média) & 3,3 & 3,1 & 3,2 & 3,2 \\
Número de pessoas na família (desvio padrão) & 3,5 & 1,5 & 1,5 & 1,4 \\
\hline \hline
\end{tabular}

Fonte: Elaboração própria a partir de microdados do Censo Demográfico 2010. 


\section{- Cadernos de Ciénclas SOCIAIS APLICADAS}

Tabela 2: Características dos trabalhadores (total de ocupados)

\begin{tabular}{l|c|c}
\hline \hline & Migrantes & Total \\
\hline Responsáveis pelo domicílio (\%) & 51,6 & 53,0 \\
Casado (\%) & 49,4 & 44,4 \\
Branco (\%) & 50,7 & 51,9 \\
Homem (\%) & 57,1 & 60,4 \\
Nível de instrução - Sem instrução e fundamental & 39,9 & 35,6 \\
incompleto (\%) & & \\
Nível de instrução - Fundamental completo e médio & 15,8 & 15,4 \\
incompleto (\%) & & \\
Nível de instrução - Médio completo e superior & 29,4 & 30,4 \\
incompleto (\%) & 14,9 & 18,6 \\
Superior completo (\%) & 40,3 & 36,8 \\
Idade (média) & 10,4 & 9,5 \\
Idade (desvio-padrão) & $\mathrm{R} \$ 1.345,78$ & $\mathrm{R} \$ 1.576,35$ \\
Rendimento do trabalho principal (média) & $\mathrm{R} \$ 2.754,51$ & $\mathrm{R} \$ 3.392,58$ \\
Rendimento do trabalho principal (desvio padrão) & $\mathrm{R} \$ 1.076,19$ & $\mathrm{R} \$ 1.315,02$ \\
Rendimento domiciliar per capita (média) & $\mathrm{R} \$ 2.909,02$ & $\mathrm{R} \$ 4.002,53$ \\
Rendimento domiciliar per capita (desvio padrão) & 3,5 & 3,3 \\
Número de pessoas na família (média) & 1,4 & 1,5 \\
Número de pessoas na família (desvio padrão) & $\mathrm{Cen} 0 \mathrm{Demog}$ \\
\hline \hline
\end{tabular}

Fonte: Elaboração própria a partir de microdados do Censo Demográfico 2010.

O percentual de trabalhadores no setor cultural considerados migrantes é superior ao do total de ocupados, exceto para o grupo de criativos direto, em que há uma pequena diferença a favor dos ocupados nas demais atividades (2,09 contra 2,02), embora as diferenças sejam marginais, como se pode notar na tabela $3^{6}$. De fato, os integrantes da classe criativa são mais móveis e costumam buscar destinos com diversidade, interação social e acesso a amenidades culturais (Markusen e Schrock, 2006).

\footnotetext{
${ }^{6}$ Essa hipótese foi corroborada pelo teste de hipótese sobre a diferença entre as proporções para as amostras de trabalhadores criativos e não criativos.
}

Página 173 Caderno de Ciências Sociais Aplicadas, Vitória da Conquista/BA, vol. 16, n² 27, ano 16, p. 158-186, jan/jun 2019. 


\section{- Cadernos de CiêncIas SOCIAIS APLICADAS}

Tabela 3: Percentual migrantes inter-regionais

\begin{tabular}{|c|c|c|c|}
\hline Migrantes inter-regionais & \multicolumn{3}{|c|}{ Criativos - Total } \\
\hline \multirow{3}{*}{ Não } & Não & $\operatorname{Sim}$ & Total \\
\hline & 98,67 & 1,33 & 100,00 \\
\hline & 97,92 & 97,86 & 97,91 \\
\hline \multirow[t]{2}{*}{$\operatorname{Sim}$} & 98,63 & 1,37 & 100,00 \\
\hline & 2,08 & 2,14 & 2,09 \\
\hline Total & 100,00 & 100,00 & \\
\hline Migrantes inter-regionais & \multicolumn{3}{|c|}{ Criativos Diretos } \\
\hline \multirow{3}{*}{ Não } & Não & $\operatorname{Sim}$ & Total \\
\hline & 99,39 & 0,61 & 100,00 \\
\hline & 97,92 & 97,72 & 97,91 \\
\hline \multirow[t]{2}{*}{$\operatorname{Sim}$} & 99,33 & 0,67 & 100,00 \\
\hline & 2,08 & 2,28 & 2,09 \\
\hline Total & 100,00 & 100,00 & \\
\hline Migrantes inter-regionais & \multicolumn{3}{|c|}{ Criativos indiretos } \\
\hline \multirow{3}{*}{ Não } & Não & $\operatorname{Sim}$ & Total \\
\hline & 99,28 & 0,72 & 100,00 \\
\hline & 97,91 & 97,98 & 97,91 \\
\hline \multirow[t]{2}{*}{$\operatorname{Sim}$} & 99,30 & 0,70 & 100,00 \\
\hline & 2,09 & 2,02 & 2,09 \\
\hline Total & 100,00 & 100,00 & \\
\hline
\end{tabular}

No que se refere às regiões de destino da classe artística, os deslocamentos seguem a mesma tendência regional do total de ocupados verificada no interregno 2005/2010, como se pode apreender na figura 1, em que são expostas as proporções dos trabalhadores ocupados que se configuram migrantes em relação ao total de ocupados dessas regiões.

Os maiores percentuais de trabalhadores migrantes, entre os trabalhadores culturais, estão no Centro-Oeste, seguido de Sul, Norte e Sudeste. A Região Centro-Oeste figura como o grande destaque como destino dos migrantes regionais, possivelmente impulsionada pela expansão de suas atividades industriais, importantes para a geração de empregos e atração de população para essa região. Vale lembrar, no entanto, que a região Sudeste, marcada pela rica diversidade cultural de seus estados, ainda mantém seu legado de destino dos migrantes criativos inter-regionais.

Página 174 Caderno de Ciências Sociais Aplicadas, Vitória da Conquista/BA, vol. 16, n 27, ano 16, p. 158-186, jan/jun 2019. 


\section{Cadernos de CiênCIas SOCIAIS ApLICADAS}

Figura1: Distribuição dos migrantes inter-regionais 2005-2010 (destino)

1.a proporção de ocupados migrantes

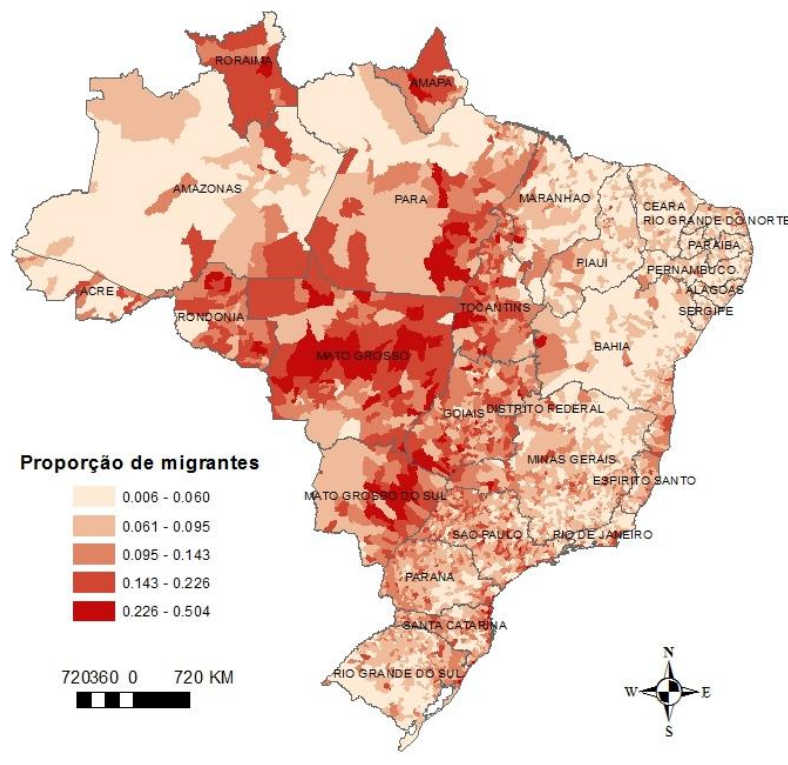

1. c proporção de criativos indiretos migrantes

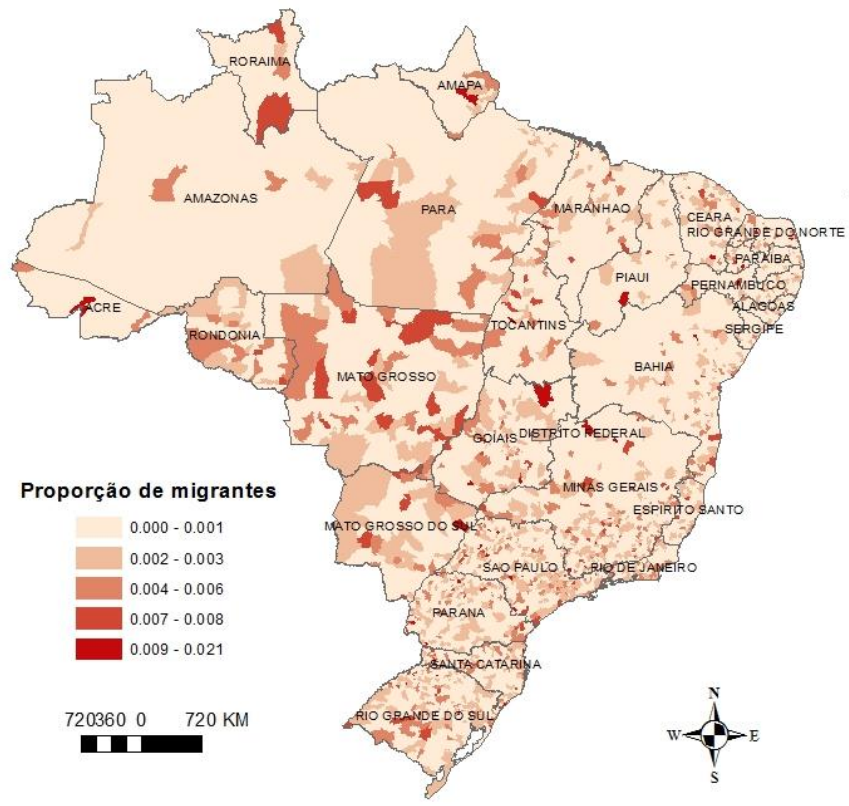

1.b proporção de criativos diretos migrantes

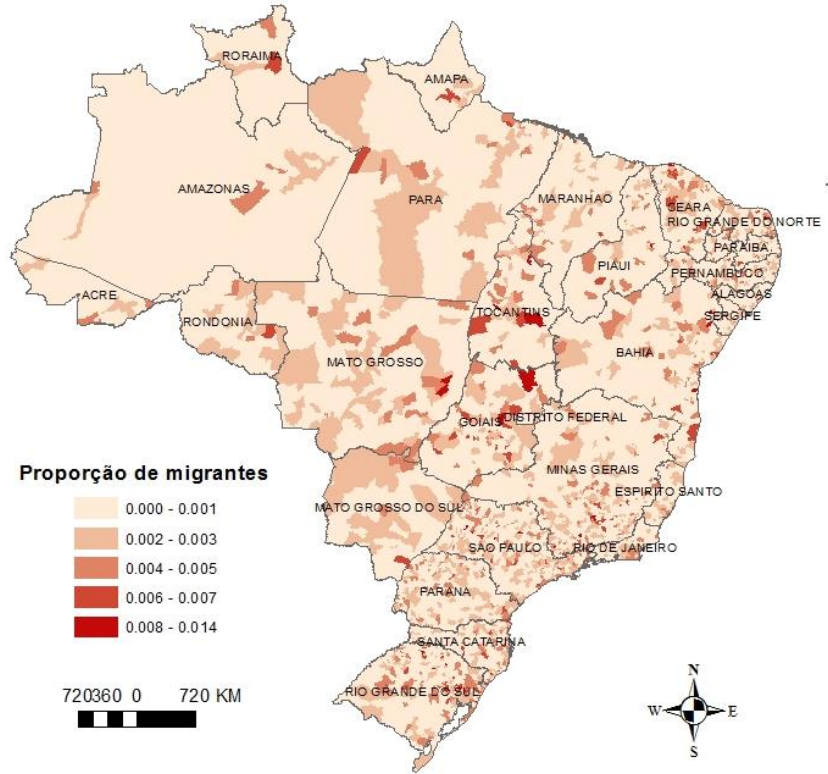

1.d proporção de criativos total migrantes

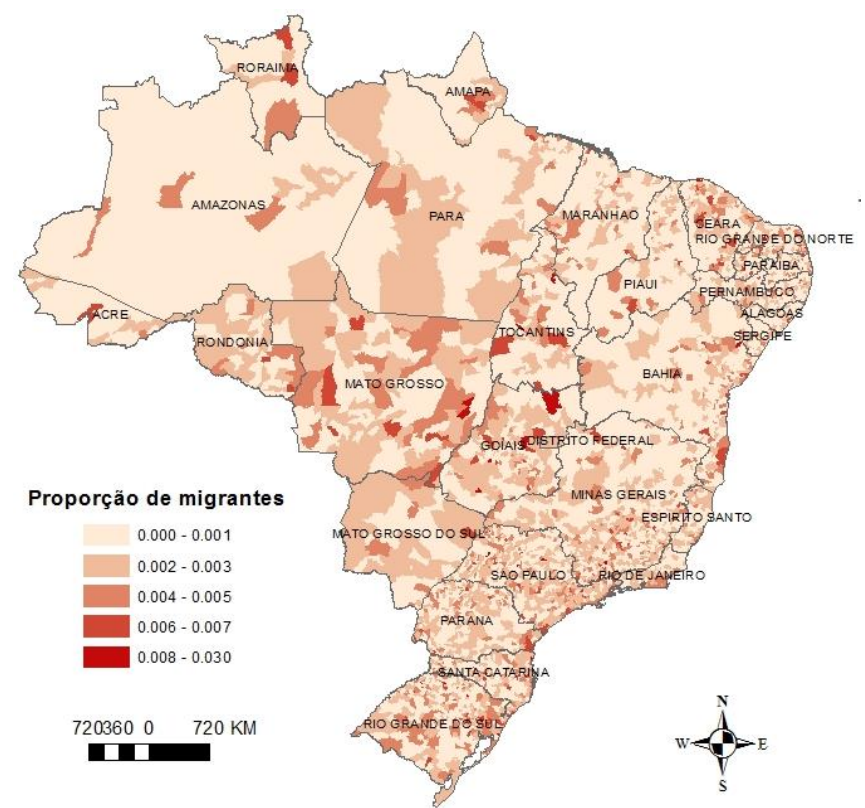

Fonte: Elaboração própria com base em microdados do Censo Demográfico 2010.

Página 175 Caderno de Ciências Sociais Aplicadas, Vitória da Conquista/BA, vol. 16, n 27, ano 16, p. 158-186, jan/jun 2019. 


\subsection{Estimação econométrica}

A tabela 4 apresenta os resultados do modelo logit multinomial estimado para todos os trabalhadores ocupados. Os efeitos para os atributos individuais sexo e idade estão de acordo com os resultados encontrados em outros estudos, revelando que a propensão a migrar é maior para os homens (Silveira Neto e Magalhães, 2004) e indivíduos mais jovens apresentam maiores probabilidades de serem migrantes em qualquer categoria, ou região. A explicação para esse fato é que indivíduos mais velhos possuem menor expectativa de ganho com a migração, logo se mostram menos dispostos a realizar algum tipo de movimento (Siqueira et al., 2008).

Indivíduos brancos apresentam menor propensão à migração para regiões Norte, Nordeste e Centro-Oeste, quando comparado aos indivíduos das demais raças. Por outro lado, possuem maiores chances de migração para destinos situados nas regiões Sudeste e Sul. Chefes de família possuem maiores chances de migração, independente da região de destino, de aproximadamente $25 \%$, em média. Por outro lado, indivíduos com cônjuge apresentam menores chances de realizar migração para quaisquer regiões. Indivíduos com família maior possuem menor chance de migrar para todas as regiões, exceto a região norte. Tais evidências corroboram o papel dos laços familiares na determinação dos custos associados à migração (Mincer, 1978).

Página 176 Caderno de Ciências Sociais Aplicadas, Vitória da Conquista/BA, vol. 16, n 27, ano 16, p. 158-186, jan/jun 2019. 


\section{- Cadernos de Ciénclas SOCIAIS APLICADAS}

Tabela 4: Resultados dos modelos para o total de ocupados

\begin{tabular}{|c|c|c|c|c|c|c|c|c|c|c|}
\hline \multirow{2}{*}{ Variáveis } & \multicolumn{2}{|c|}{ Norte } & \multicolumn{2}{|c|}{ Nordeste } & \multicolumn{2}{|c|}{ Sudeste } & \multicolumn{2}{|l|}{ Sul } & \multicolumn{2}{|c|}{ Centro-Oeste } \\
\hline & Coeficiente & R.R.R. & Coeficiente & R.R.R. & Coeficiente & R.R.R. & Coeficiente & R.R.R. & Coeficiente & R.R.R. \\
\hline Idade & $-0,055^{* * *}$ & 0,946 & $-0,035^{* * *}$ & 0,965 & $-0,044 * * *$ & 0,957 & $-0,040^{* * *}$ & 0,961 & $-0,042^{* * *}$ & 0,959 \\
\hline Idade2 & $0,000^{* * *}$ & 1,000 & $0,000^{* * *}$ & 0,999 & $0,000^{* * *}$ & 1,000 & 0,000 & 0,999 & $0,000^{* * *}$ & 0,999 \\
\hline Homem & $0,342^{* * *}$ & 1,408 & $0,224 * * *$ & 1,250 & $0,181^{* * *}$ & 1,198 & $0,082^{* * *}$ & 1,085 & $0,212^{* * *}$ & 1,236 \\
\hline Branco & $-0,795^{* * *}$ & 0,451 & $-0,622 * * *$ & 0,537 & $0,128^{* * *}$ & 1,136 & $1,118^{* * *}$ & 3,264 & $-0,304 * * *$ & 0,738 \\
\hline Casado & $-0,280 * * *$ & 0,756 & $-0,100 * * *$ & 0,905 & $0,057 * * *$ & 1,058 & $-0,093 * * *$ & 0,911 & $-0,033^{* * *} *$ & 0,967 \\
\hline Chefe & $0,235^{* * *}$ & 1,265 & $0,186^{* * *}$ & 1,204 & $0,130^{* * *}$ & 1,138 & $0,166^{* * *}$ & 1,180 & $0,231^{* * *}$ & 1,260 \\
\hline nho da família & $0,010^{* * *}$ & 1,009 & $-0,087 * * *$ & 0,916 & $-0,146^{* * *}$ & 0,864 & $-0,173 * * *$ & 0,841 & $-0,128 * * *$ & 0,879 \\
\hline Instrução & Omitida & & Omitida & & Omitida & & Omitida & & Omitida & \\
\hline $\begin{array}{l}\text { ompleto e médio } \\
\text { ncompleto }\end{array}$ & $-0,114 * * *$ & 0,892 & $-0,171 * * *$ & 0,843 & $-0,018^{* * *}$ & 0,982 & $0,015^{* * *}$ & 1,014 & $-0,104 * * *$ & 0,901 \\
\hline $\begin{array}{l}\text { o completo e } \\
\text { or incompleto }\end{array}$ & $-0,065^{* * *}$ & 0,937 & $0,013^{* * *}$ & 1,012 & $-0,055^{* * *}$ & 0,946 & $1 * * *$ & 0,843 & $-0,247 * * *$ & 0,781 \\
\hline $\begin{array}{l}\text { erior completo } \\
\text { de formalidade }\end{array}$ & $0,305^{* * *}$ & 1,356 & $0,284^{* * *}$ & 1,328 & $0,364^{* * *}$ & 1,438 & $-0,031 * * *$ & 0,969 & $0,174^{* * *}$ & 1,189 \\
\hline carteira/func. & $-0,593 * * *$ & 0,553 & $-0,740 * * *$ & 0,477 & $0,818^{* * *}$ & 2,265 & $0,237 * * *$ & 1,267 & $0,364^{* * *}$ & 1,438 \\
\hline Sem carteira & $-0,126^{* * *}$ & 0,882 & $-0,125^{* * *}$ & 0,882 & $0,699 * * *$ & 2,011 & $0,037 * * *$ & 1,037 & $0,425^{* * *}$ & 1,529 \\
\hline própria/empreg & $-0,272 * * *$ & 0,762 & $-0,459 * * *$ & 0,631 & $0,533^{* * *}$ & 1,704 & $0,081^{* * *}$ & 1,084 & $0,144^{* * *}$ & 1,154 \\
\hline io remunerado & Omitida & & Omitida & & Omitida & & Omitida & & Omitida & \\
\hline Observações & 66.511 .779 & & 66.511 .779 & & 66.511 .779 & & 66.511 .779 & & 66.511 .779 & \\
\hline Pseudo R2 & 0,323 & & 0,323 & & 0,323 & & 0,323 & & 0,323 & \\
\hline Prob $>$ Chi & 0,000 & & 0,000 & & 0,000 & & 0,000 & & 0,000 & \\
\hline
\end{tabular}

Nota: Nível de significância: $* 0.10, * * 0.05, \mathrm{e}^{* * *} 0.01$, respectivamente.

Fonte: elaboração própria com base nos resultados dos modelos.

Com relação ao nível de instrução, os resultados revelam que indivíduos com ensino fundamental e médio completos possuem menor chance de migrar em relação aos indivíduos sem instrução (categoria de referência). Entretanto, no que se refere aos indivíduos com ensino superior completo, observa-se maior propensão a realizar migração para todos os destinos, excetuando a região sul. Esse resultado está em consonância com Faggian e McCann (2009), segundo os quais pessoas altamente instruídas possuem custos mais baixos e retornos superiores na migração, pois possuem maior e melhor acesso à informação a custos menores, e oportunidades em lugares alternativos.

No que se refere ao grau de formalidade do mercado de trabalho, os resultados indicam que indivíduos com carteira assinada possuem maior chance de estar ocupado nas regiões Nordeste, Sudeste, Sul e Centro-Oeste, e menor chance de estar ocupado na Região Norte, quando comparado ao

Página 177 Caderno de Ciências Sociais Aplicadas, Vitória da Conquista/BA, vol. 16, n² 27, ano 16, p. 158-186, jan/jun 2019. 
indivíduo não remunerado (categoria de referência). Migrantes que trabalham por conta própria apresentam maior possibilidade de ocupação no Sudeste em face dos não remunerados.

Foram estimados modelos segundo diferentes tipos de região de destino para amostra de trabalhadores pertencentes ao setor criativo direto (tabela 5). Os resultados para os trabalhadores culturais apontam que a probabilidade de migração é maior para os jovens e homens, nesse último caso, excetua-se a região Norte do País. Semelhante à amostra do total de ocupados, brancos possuem menor chance de migração para regiões, Norte, Nordeste e Centro-Oeste, quando comparado aos indivíduos das demais raças.

Tabela 5: Resultados dos modelos logit para amostra de trabalhadores criativos diretos

\begin{tabular}{|c|c|c|c|c|c|c|c|c|c|c|}
\hline \multirow{2}{*}{ Variáveis } & \multicolumn{2}{|c|}{ Norte } & \multicolumn{2}{|c|}{ Nordeste } & \multicolumn{2}{|c|}{ Sudeste } & \multicolumn{2}{|l|}{ Sul } & \multicolumn{2}{|c|}{ Centro-Oeste } \\
\hline & Coeficiente & R.R.R. & Coeficiente & R.R.R. & Coeficiente & R.R.R. & Coeficiente & R.R.R. & Coeficiente & R.R.R. \\
\hline Idade & $0,137 * * *$ & 1,147 & $-0,028^{* * *}$ & 0,972 & $-0,021 * * *$ & 0,979 & $-0,101 * * *$ & 0,903 & $-0,064 * * *$ & 0,938 \\
\hline Idade2 & $-0,002^{* * *}$ & 0,998 & 0,000 & 1,000 & $0,000^{*}$ & 0,999 & $0,001 * * *$ & 1,000 & $0,000 * * *$ & 1,000 \\
\hline Homem & $0,131^{* * *}$ & 1,140 & $0,233^{* * *}$ & 1,262 & $-0,038^{* *}$ & 0,962 & $-0,143^{* * *}$ & 0,866 & $0,118^{* * *}$ & 1,124 \\
\hline Branco & $-0,771 * * *$ & 0,462 & $-0,819 * * *$ & 0,440 & $0,224 * * *$ & 1,251 & $1,428^{* * *}$ & 4,173 & $-0,231 * * *$ & 0,793 \\
\hline Casado & $-0,494 * * *$ & 0,610 & $-0,262 * * *$ & 0,769 & $0,017 * * *$ & 1,017 & $-0,203^{* * *}$ & 0,816 & $0,180 * * *$ & 1,197 \\
\hline Chefe & 0,069 & 1,071 & $0,187 * * *$ & 1,206 & $0,103^{* * *}$ & 1,108 & $0,135^{* * *}$ & 1,144 & $0,180^{* * *}$ & 1,196 \\
\hline Tamanho da família & $-0,096^{* * *}$ & 0,908 & $-0,107 * * *$ & 0,898 & $-0,157 * * *$ & 0,854 & $-0,158^{* * *}$ & 0,853 & $-0,119 * * *$ & 0,887 \\
\hline Sem Instrução & Omitida & & Omitida & & Omitida & & Omitida & & Omitida & \\
\hline $\begin{array}{l}\text { Fund. completo e médio } \\
\text { incompleto }\end{array}$ & $0,289 * * *$ & 1,334 & 0,046 & 1,047 & $0,277 * * *$ & 1,319 & $-0,014$ & 0,986 & $-0,162 * * *$ & 0,850 \\
\hline $\begin{array}{l}\text { Médio completo e } \\
\text { superior incompleto }\end{array}$ & $-0,070$ & 0,932 & $-0,047^{*}$ & 0,953 & $0,540^{* * *}$ & 1,716 & $-0,157 * * *$ & 0,854 & 0,053 & 1,054 \\
\hline Superior completo & $-0,246^{* * *}$ & 0,781 & $-0,135^{* * *}$ & 0,874 & $0,842^{* * *}$ & 2,320 & $-0,769 * * *$ & 0,463 & $-0,330 * * *$ & 0,719 \\
\hline \multicolumn{11}{|l|}{ Grau de formalidade } \\
\hline Com carteira/func. & $0,208^{* * *}$ & 0,208 & $-0,869 * * *$ & 0,419 & $-0,792^{* * *}$ & 0,452 & 0,059 & 1,060 & 15,418 & 497 \\
\hline Sem carteira & $0,259 * * *$ & 0,259 & $-0,321 * * *$ & 0,725 & $-0,573 * * *$ & 0,563 & $-0,368^{* * *}$ & 0,692 & 15,525 & 552 \\
\hline Conta própria/empreg & $0,479 * * *$ & 0,479 & $-0,341 * * *$ & 0,711 & $-0,385^{* * *}$ & 0,680 & $-0,223^{*}$ & 0,800 & 15,650 & 626 \\
\hline Não remunerado & Omitida & & Omitida & & Omitida & & Omitida & & Omitida & \\
\hline Observações & 403.608 & & 403.608 & & 403.608 & & 403.608 & & 403.608 & \\
\hline Pseudo R2 & 0,035 & & 0,035 & & 0,035 & & 0,035 & & 0,035 & \\
\hline Prob $>$ Chi & 0,000 & & 0,000 & & 0,000 & & 0,000 & & 0,000 & \\
\hline
\end{tabular}

Nota: Nível de significância: * $0.10, * * 0.05, \mathrm{e}^{* * *} 0.01$, respectivamente.

Fonte: elaboração própria com base nos resultados dos modelos.

Profissionais culturais diretos na posição de chefes de família possuem maiores chances de migração para todas as regiões brasileiras, com exceção da região Norte. Por outro lado, indivíduos 
com cônjuge apresentam menores chances de realizar migração para as regiões Sudeste e Centro-Oeste. Indivíduos com família maior possuem menor chance de migrar para todas as regiões.

No que se refere ao grau de instrução, profissionais criativos com maior escolaridade (ensino superior completo) possuem maior chance de migrar apenas para o Sudeste. Outro aspecto relacionado à instrução da classe artística/cultural ocupada em profissões diretas é que os menos escolarizados apresentam maior chance de migração para a Região Norte.

No que tange ao grau de formalidade dos trabalhadores culturais diretos, cabe sublinhar que indivíduos com carteira assinada possuem maior chance de estar ocupado na região Norte, em relação aos profissionais não remunerados dessa categoria, e menores chances de estar ocupado nas Regiões Nordeste e Sudeste, diferentemente do observado para o total de ocupados, quando comparados ao indivíduo não remunerado. Migrantes que trabalham por conta própria apresentam maior possibilidade de ocupação no Nordeste, enquanto para o total de ocupados a região de maior chance de ocupação é o Sudeste.

De maneira adicional, foi estimado modelo multinomial idêntico aos dois anteriores, diferenciando-se apensas a amostra de trabalhadores, agora composta pelos trabalhadores indiretamente envolvidos em atividades culturais. Os resultados desse modelo são explicitados na tabela 6.

Página 179 Caderno de Ciências Sociais Aplicadas, Vitória da Conquista/BA, vol. 16, n 27, ano 16, p. 158-186, jan/jun 2019. 


\section{Cadernos de CiênCIas SOCIAIS APLICADAS}

Tabela 6: Resultados dos modelos logit para amostra de trabalhadores criativos indiretos

\begin{tabular}{|c|c|c|c|c|c|c|c|c|c|c|}
\hline \multirow{2}{*}{ Variáveis } & \multicolumn{2}{|c|}{ Norte } & \multicolumn{2}{|c|}{ Nordeste } & \multicolumn{2}{|c|}{ Sudeste } & \multicolumn{2}{|l|}{ Sul } & \multicolumn{2}{|c|}{ Centro-Oeste } \\
\hline & Coeficiente & R.R.R. & Coeficiente & R.R.R. & Coeficiente & R.R.R. & Coeficiente & R.R.R. & Coeficiente & R.R.R. \\
\hline Idade & $-0,105^{* * *}$ & 0,900 & $-0,026^{* * *}$ & 0,974 & $-0,077 * * *$ & 0,925 & $-0,027 * * *$ & 0,973 & $0,033 * * *$ & 1,033 \\
\hline Idade2 & $0,001 * * *$ & 1,000 & 0,000 & 0,999 & $0,000^{* * *}$ & 1,000 & 0,000 & 0,999 & $-0,000 * * *$ & 0,999 \\
\hline Homem & $0,109 * *$ & 1,115 & $0,046^{*}$ & 1,047 & $-0,126 * * *$ & 0,881 & $-0,017$ & 0,983 & $-0,106 * * *$ & 0,899 \\
\hline Branco & $-0,532 * * *$ & 0,587 & $-0,793 * * *$ & 0,452 & $0,179 * * *$ & 1,196 & $1,037 * * *$ & 2,822 & $-0,322 * * *$ & 0,724 \\
\hline Casado & $-0,220 * * *$ & 0,802 & $0,055^{* * *}$ & 1,056 & $0,226^{* * *}$ & 1,253 & $-0,126^{* * *}$ & 0,881 & $0,271 * * *$ & 1,310 \\
\hline Chefe & $0,120 * * *$ & 1,127 & $0,451 * * *$ & 1,569 & $0,220 * * *$ & 1,245 & $0,173 * * *$ & 1,189 & $0,248 * * *$ & 1,281 \\
\hline Tamanho da família & $0,031 *$ & 1,032 & $-0,141 * * *$ & 0,868 & $-0,219 * * *$ & 0,803 & $-0,332 * * *$ & 0,717 & $-0,211 * * *$ & 0,809 \\
\hline Sem Instrução & Omitida & & Omitida & & Omitida & & Omitida & & Omitida & \\
\hline $\begin{array}{l}\text { Fund. completo e médio } \\
\text { incompleto }\end{array}$ & $-0,416^{* * *}$ & 0,659 & $-0,289 * * *$ & 0,748 & $-0,113 * * *$ & 0,893 & 0,017 & 1,017 & $-0,294 * * *$ & 0,744 \\
\hline $\begin{array}{l}\text { Médio completo e } \\
\text { superior incompleto }\end{array}$ & $-0,394 * * *$ & 0,674 & $-0,153 * * *$ & 0,857 & $0,102^{* * *}$ & 1,107 & $-0,058$ & 0,943 & $-0,292^{* * *}$ & 0,746 \\
\hline Superior completo & $-0,661 * * *$ & 0,516 & 0,042 & 1,042 & $0,529 * * *$ & 1,696 & 0,054 & 1,055 & $-0,031$ & 0,969 \\
\hline Grau de formalidade & & & & & & & & & & \\
\hline Com carteira/func. & $-0,187$ & 0,829 & $-1,802^{* * *}$ & 0,164 & $-0,096$ & 0,908 & 0,347 & 1,414 & $-0,228$ & 0,795 \\
\hline Sem carteira & 0,097 & 1,102 & $-0,957 * * *$ & 0,384 & 0,043 & 1,044 & 0,344 & 1,410 & 0,089 & 1,092 \\
\hline Conta própria/empreg & $-0,160$ & 0,852 & $-1,184 * * *$ & 0,305 & $-0,049$ & 0,952 & $0,487 * *$ & 1,626 & $-0,195$ & 0,823 \\
\hline Não remunerado & Omitida & & Omitida & & Omitida & & Omitida & & Omitida & \\
\hline Observações & 529.050 & & 529.050 & & 529.050 & & 529.050 & & 529.050 & \\
\hline Pseudo R2 & 0,037 & & 0,037 & & 0,037 & & 0,037 & & 0,037 & \\
\hline Prob $>$ Chi & 0,000 & & 0,000 & & 0,000 & & 0,000 & & 0,000 & \\
\hline
\end{tabular}

Nota: Nível de significância: * $0.10, * * 0.05, \mathrm{e}^{* * *} 0.01$, respectivamente.

Fonte: elaboração própria com base nos resultados dos modelos.

Trabalhadores culturais indiretos migrantes cujos destinos são as Regiões, Norte, Nordeste, Sudeste ou Sul são mais jovens. Homens apresentam maior propensão a migrar para o Norte ou Nordeste, e menor chance de ter como destino as regiões Sul ou Sudeste. Diferentemente da amostra de criativos diretos, a variável sexo não apresentou coeficiente estatisticamente significativo para a Região CentroOeste.

Chefes de família possuem maiores chances de migração para todas as regiões brasileiras. Por outro lado, indivíduos com cônjuge apresentam menores chances de realizar migração para as regiões Norte e Sul, enquanto os artistas diretos apresentaram menor propensão aos destinos Sudeste e CentroOeste. Indivíduos com família maior possuem menor chance de migrar para todas as regiões, à exceção da Região Norte.

No que se refere ao grau de instrução, profissionais criativos indiretos com ensino superior completo possuem maior chance de migrar apenas para o Sudeste. Outro aspecto relacionado à

Página 180 Caderno de Ciências Sociais Aplicadas, Vitória da Conquista/BA, vol. 16, n 27, ano 16, p. 158-186, jan/jun 2019. 
instrução da classe artística/cultural ocupada em profissões diretas é que os mais escolarizados apresentam menor chance de migração para a Região Norte.

No que tange ao grau de formalidade dos trabalhadores culturais indiretos, cabe sublinhar que esse aspecto parece pouco significar para esses profissionais. Apenas para a região Nordeste as categorias de formalidade foram significativas, com menores chances de migrar para indivíduos com carteira assinada, sem carteira ou conta própria, quando comparados aos não remunerados. Por outro lado, indivíduos ocupados no setor criativo indireto que trabalham por conta própria ou são empregadores apresentam maior chance de migrar para a Região Sul.

Por sua vez, nota-se que a probabilidade de migrar varia entre as grandes regiões, cujos determinantes são distintos em características individuais observadas, fato observado tanto para trabalhadores ocupados em geral e para trabalhadores pertencentes ao setor criativo direto e indireto.

\section{Considerações finais}

Este estudo buscou identificar fatores individuais da migração de ocupados do setor cultural/criativo no Brasil segundo grandes regiões. O foco da abordagem migratória esteve contido em perspectiva de curto prazo, cujo critério foi o de data fixa. O tratamento metodológico foi realizado pelo modelo logit multinomial, utilizando microdados de Censo Demográfico Brasileiro de 2010.

Com base nos resultados dos modelos multinomiais estimados, foi possível concluir que características individuais observadas são importantes na determinação da migração de trabalhadores, sejam estes criativos ou não. Outro aspecto relevante é a diferença nos efeitos e papéis desempenhados por essas características quando os destinos das migrações são diferentes. Homens e jovens possuem maior chance de realizar qualquer tipo de migração. Indivíduos com ensino superior completo são mais móveis em relação aos demais, o que vai de encontro aos resultados encontrados por Markusen e Schrock (2006) e Florida (2002).

Indivíduos brancos são menos propensos à migração para as Regiões Norte, Nordeste e Centro-Oeste, quando comparados aos indivíduos das demais raças. Por outro lado, possuem maiores chances de migração para destinos situados nas regiões sudeste e sul. Chefes de família possuem maiores chances de migração, independentemente da região de destino, de aproximadamente $25 \%$, em média. Por outro lado, indivíduos com cônjuge apresentam menores chances de realizar migração para quaisquer regiões. Indivíduos com família maior possuem menor chance de migrar para todas as regiões, exceto a região Norte.

Página 181 Caderno de Ciências Sociais Aplicadas, Vitória da Conquista/BA, vol. 16, n 27, ano 16, p. 158-186, jan/jun 2019. 
Para o caso particular dos profissionais criativos, no que se refere ao grau de instrução, profissionais criativos com ensino superior completo possuem maior chance de migrar para o Sudeste. Outro aspecto relacionado à instrução da classe artística/cultural ocupada em profissões diretas é que os menos escolarizados apresentam maior chance de migração para a Região Norte. Indivíduos com carteira assinada possuem maior chance de estar ocupado na região Norte, em relação aos profissionais não remunerados dessa categoria, e menores chances de estar ocupado nas Regiões Nordeste e Sudeste, diferente do observado para o total de ocupados, quando comparados ao indivíduo não remunerado. Migrantes que trabalham por conta própria apresentam maior possibilidade de ocupação no Nordeste, enquanto para o total de ocupados a região de maior chance de ocupação é o Sudeste.

Nota-se a importância de compreender os determinantes da mobilidade geográfica dos trabalhadores inseridos em atividades culturais uma vez que estas estão associadas ao desenvolvimento econômico e social das regiões em que se situam. Nesse sentido, indagações surgem com base nessa análise, e são relevantes para auxiliar o desenho de políticas públicas voltadas à atração e retenção dessa parcela dos trabalhadores ocupados, visando ainda à condução de trabalhadores qualificados, identicamente cativados por amenidades culturais e responsáveis por grande parcela de transferência de conhecimento tácito, fundamental ao desenvolvimento econômico e social das regiões. Sob esse prisma, deve-se almejar o maior entendimento da dinâmica migratória dos trabalhadores culturais, bem como dos elementos geográfico e social dos lugares de retenção dessa parcela da população para predizer os efeitos conjuntos de atributos individuais e regionais preponderantes à mobilidade espacial desses indivíduos e, assim, subsidiar a construção de ambientes propícios aos trabalhadores criativos, tão importantes ao desenvolvimento local e regional.

\section{Referências}

ANDRIENKO, Y.; GURIEV, S. Determinants of Interregional Mobility in Russia: Evidence from Panel Data. Economic of Transition, v. 12, p. 1-27. 2004.

BORJAS, G. J Economics of Migration. In: International encyclopedia of the social and behavioral sciences. Boston: Elsevier, 2000.

BORJAS, G.J. "Labor mobility”. In: BORJAS, G.J. Labor economics. Singapura: McGraw-Hill Book Co, 1996. p. 279-317.

BOSCHMA, R. A.; FRITSCH, M. Creative class and regional growth: Empirical evidence from seven European countries. Economic Geography, 85.4 (2009): 391-423.

Página 182 Caderno de Ciências Sociais Aplicadas, Vitória da Conquista/BA, vol. 16, n 27, ano 16, p. 158-186, jan/jun 2019. 
BOVER, O.; ARELLANO, M. Learning about migration decisions from de migrants: using complementary dataset to model intra-regional migrations in Spain. Population Economics, v. 15, p. 357-380, 2002.

CARVALHO, J. A. M. de. \& RIGOT'TI, J.I.R. Os dados censitários brasileiros sobre migrações internas: algumas sugestões para análise. Revista Brasileira de Estudos Populacionais. São Paulo, v.15, n.2, 1998.

CUNHA, J. M. P. da; BAENINGER, R. Cenários da Migração no Brasil nos anos 90. Cadernos do CRH, Salvador, v. 18, n. 43, jan./abril. 2005.

CUNHA, J. M. P. Retratos da mobilidade espacial no Brasil: Os censos demográficos como fonte de dados. Revista Interdisciplinar da Mobilidade Humana, Brasília, Ano XX, ${ }^{\circ}$ 39, p. 29-50, jul./dez. 2012.

DAvANZO, J. Repeat Migration in the United States: Who Moves Back and Who Moves On? The Review of Economics and Statistics, v. 65, n. 4, p. 552-59, 1983.

DIRK, H. Cultures in Contact: World Migrations in the Second Millennium, capítulo 1, Duke University Press, London.

DUSTMANN, Christian. Return migration, wage differentials, and the optimal migration duration. European Economic Review, v 47, p. 353-367, 2003.

FAGGIAN, A., MCCANN, P. Human capital and regional development. In, Capello, Roberta and Nijkamp, Peter (eds.) Handbook of Regional Growth and Development Theories. Cheltenham, UK, Edward Elgar, 131-151. 2009.

FLORIDA, R. The economic geography of talent. Annals of the Association of American Geographers, v. 92, n. 4, p. 743-755, 2002.

FLORIDA, R. The Rise of the Creative Class and how its transforming work, leisure, community \& everyday life. New York: Basic Books, 2002.

GARBER-YONTES, B. E. The economics of amenities and migration in the Pacific Northwest: a review of selected literature with implications for national forest management. General Technical Report. PNW-GTR-617. USDAForest Service, Pacific Northwest Research Station, Portland, OR. 2004.

GOLGHER, A. Fundamentos da migração. Texto para discussão, no 231. Belo Horizonte: UFMG/CEDEPLAR, 2004.

A distribuição de indivíduos qualificados nas regiões metropolitanas brasileiras: a influência do entretenimento e da diversidade populacional. Nova Economia, Belo Horizonte, v. 21, n. 1, p. 109134, jan./abr., 2011.

Página 183 Caderno de Ciências Sociais Aplicadas, Vitória da Conquista/BA, vol. 16, n² 27, ano 16, p. 158-186, jan/jun 2019. 
As cidades e a classe criativa no Brasil: diferenças espaciais na distribuição de indivíduos qualificados nos municípios brasileiros. Revista brasileira de Estudos da População. São Paulo, v. 25, n. 1, p. 109-129, jan./jun. 2008.

GREENWOOD, M. Human Migration: Theory, Models, and Empirical Studies. Journal of Regional Science, v.25, p.521-544, 1985.

HANSEN, H. K.; NIEDOMYSL, T. Migration of the creative class: evidence from Sweden. Journal of Economic Geography, 9.2 (2009): 191-206.

HARRIS, J., TODARO, M. Migration, Unemployment and Development: A Two-Sector Analysis. The American Economic Review, Vol. 60, No. 1, pp. 126-142. (1970).

HOX, J. Multilevel Analysis: Techniques and Applications. New Jersey: Lawrence Erlbaum Associates, Inc. 2002.

JUSTO, W. R.; SILVEIRA NETO, R. M. Quem são e para onde vão os migrantes no Brasil?O perfil do migrante interno brasileiro. Revista ABET. vol. VIII — n. 1, 2009.

KELLY, E.; O'HAGAN, J. Geographic clustering of economic activity: The case of prominent western visual artists. Journal of Cultural Economics, 31.2 (2007): 109-128.

KULU, H., BILARI, F. C. "Multilevel analysis of internal migration in a transitional country: the case of Estonia". Regional Estudies, v. 38, n. 6, p. 697-696, 2004.

KUZNETS, SIMON, THOMAS, DOROTHY, et al. Population Redistribution and Economic Growth-United States, 1870-1950. 3 vols. Philadelphia: American Philosophical Soc., 1957, 1960, 1964. LEE, E. A Theory of Migration, Demography, v. 03, n. 01, p.47-57, 1966.

LUCAS, R. E. B. The effects of proximity and transportation on developing country population migrations. Journal of Economic Geography, v. 01, n. 03, p. 323-339, nov., 2000.

MARKUSEN, A.; SCHROCK, G. The artistic dividend: urban artistic specialisation and economic development implications. Urban studies, 43.10 (2006): 1661-1686.

MARTIN-BRELOT, H., et al. The spatial mobility of the 'creative class': A European perspective." International Journal of Urban and Regional Research, 34.4 (2010): 854-870.

MATA, D., OLIVEIRA, C., PIN, C., RESENDE, G. Quais Características das Cidades Determinam a Atração de Migrantes Qualificados? Revista Econômica do Nordeste, Fortaleza, v. 38, $\mathbf{n}^{\circ}$ 3, jul-set. 2007.

NEWBOLD, K. Bruce e BELL Martin. Return and Onward Migration in Canada and Australia: Evidence From Fixed Interval Data. International Migration Review, v.35, n.4, p. 1157-1187, 2001.

Página 184 Caderno de Ciências Sociais Aplicadas, Vitória da Conquista/BA, vol. 16, n 27, ano 16, p. 158-186, jan/jun 2019. 
OLIVEIRA, K.F.; JANNUZI, P.M. "Motivos para migração no Brasil e retorno ao nordeste: padrões etários, por sexo e origem/destino". São Paulo em Perspectiva, v. 19, n. 4, p. 134-143, dez. 2005.

PEKKALA, S. Migration Flows in Finland: Regional Differences in Migration Determinants and Migrant Types. International Regional Science Review, v. 26, n. 4, p. 466-482, 2003.

PORTER, M. The competitive advantage of nations. London: Macmillan, 1990.

QUEIROZ, B. L.; GOLGHER, A. B. Human capitals differentials across municipalities and states in Brazil. Population review, v.48, p.1-1, 2008.

RALLET, A.; TORRE, A. On geography and technology: Proximity relations in localised innovation networks. In: STEINER, M. (Ed.) Clusters and regional specialisation: On geography, technology and networks. London: Pion, 1998.

RAUDENBUSH, S. W., BRYK, A. S. Hierarchical linear models: applications and data analysis methods.2.ed. Londres, Nova Deli: Sage, 2002. 265p.

RIGOTTI, J. I. R. Técnicas de Mensuração das migrações, a partir de dados censitários: aplicação aos casos de Minas Gerais e São Paulo. 1999. Tese (Doutorado CEDEPLAR). Universidade Federal de Minas Gerais, Belo Horizonte.

SAHOTA, G. S. An Economic analysis of Internal Migration in Brazil. Journal of Political Economy, v.76, n.2, p.218-245, 1968.

SILVEIRA NETO, R.; MAGALHÃES, A. O progresso econômico domigrante em São Paulo: evidências a partir dos censos demográficos de 1991 e 2000.Anais do III Encontro da Associação Brasileira de Estudos Regionais. Belo Horizonte, 2004.

SIQUEIRA, L. B. O.; MAGALHÃES, A. M.; NETO, R. M. S. Perfil do migrantes de retorno no Brasil: evidências a partir do Censo de 2000. In: ENCONTRO NACIONAL DE ESTUDOS POPULACIONAIS, 16, 2008, Caxambu. Anais. Caxambu: ABEP, 2008.

SJAASTAD, L. The costs and returns of human migration. Journal of Political Economy, v. 70, n.5, out, 1962, p. 80-93.

STARK, O., BLOOM, D. The American Economic Review, vol. 75, n. ${ }^{\circ}$ 2, Papers and Proceedings of the Ninety- Seventh Annual Meeting of the American Economic Association (May, 1985), pp. 173178.

VANDERKAMP, J. Migration flows, their determinants and effects of return migration. Journal of Political Economy, v.79, p.1012-1031, sep/out. 1971.

Página 185 Caderno de Ciências Sociais Aplicadas, Vitória da Conquista/BA, vol. 16, n 27, ano 16, p. 158-186, jan/jun 2019. 
VISZT, E.; PLANK, Z.; BORSI, B. Mobility of Human Resources in Hungary: An Analysis and a Proposal for Regular Collection of Statistics. In: OECD (Org). Innovative people: mobility of skilled personnel in national innovation systems. p. 175-188, 2001.

WOOLDRIDGE, J. M. Econometric analysis of cross section and panel data. MIT Press: London, 2002. 